\title{
PEMBENTUKAN KARAKTER ISLAMI DALAM HADIS DAN IMPLIKASINYA PADA JALUR PENDIDIKAN NON FORMAL
}

\author{
Yuliharti \\ Universitas Islam Negeri Sultan Syarif Kasim Riau, Indonesia \\ Email: yuliharti@uin-suska.ac.id
}

\begin{abstract}
Education plays a very important role in ensuring the survival of the state and nation. The rise of various types of crime, brawls between students, cases of underage children, and the use of illegal drugs, as well as corruption cases that are increasingly becoming increasingly an indication of moral decline or moral decline. Therefore, the formation of Islamic character both in the family, the school and in the community becomes a necessity and necessity and must work together and support each other. Therefore, in the current era of globalization, it is very important to look for appropriate efforts as a reference in shaping Islamic character so that it can give birth to a generation that excels in character. Modeling the pattern of the Prophet Muhammad in shaping the character of the generation of friends from the jahiliyyah character into an Islamic character is a smart and appropriate effort for now and therefore, he is known as a prophet who is also a very successful educator in the world of education. This paper aims to reveal the formation of Islamic character that has been carried out by the Prophet and its implications in the path of non-formal education.
\end{abstract}

Keywords: Islamic character, prophetic hadith, non-formal education

\section{A. Pendahuluan}

Permasalahan yang dihadapi dunia pendidikan di era milenium yang ditandai dengan kemajuan teknologi informasi dan komunikasi saat ini adalah semakin maraknya tindakan kekerasan di kalangan anak dan remaja, tawuran antar pelajar dan mahasiswa, tindakan bullying, persekusi, menyontek berjamaah saat ujian nasional, maraknya kasus korupsi, kenakalan remaja, hamil di luar nikah, narkoba, dan tindakan kriminal dan dekadensi moral lain sebagainya.

Fenomena di atas tentunya menimbulkan pertanyaan, yaitu seberapa jauh pengaruh pendidikan agama, khususnya pendidikan agama Islam yang diberikan di sekolah dan madrasah? Atau seberapa besar pengaruh materi-materi pendidikan agama Islam di sekolah terhadap munculnya prilaku atau karakter anak didik? 
Beberapa kalangan menilai bahwa pendidikan agama Islam belum mampu untuk menggarap prilaku, sikap dan moral bangsa ini. ${ }^{1}$ Bahkan dianggap bahwa pendidikan agama gagal dalam menanamkan nilai-nilai Islam dan mengatasi problema bangsa ini. ${ }^{2}$ KH. Sahal Mahfudz sebagaimana dikutip oleh Sutrisno, menyebutkan kegagalan ini sebagai kegagalan pendidikan agama di sekolah, yang menurutnya terlalu menekankan pada pencapaian nilai ujian (kuantitatif) sehingga mengabaikan internalisasi nilai-nilai akhlak (kualitatif). Sementara Gus Salahuddin Wahid menyatakan bahwa pendidikan agama yang mengalami kegagalan tidak hanya pendidikan agama Islam (PAI), tapi semua pendidikan agama. Buktinya para pelaku tindakan kriminal dan kebobrokan moral juga berasal dari penganut dari berbagai agama. Mochtar Buchori menilai kegagalan pendidikan agama di sekolah disebabkan karena praktik pendidikannya hanya memperhatikan aspek kognitif semata dari pertumbuhan kesadaran nilai-nilai (agama) dan mengabaikan pembinaan aspek afektif dan konatif-volutif, yakni kemauan dan tekad untuk mengamalkan nilai-nilai ajaran agama sehingga terjadi kesenjangan antara pengetahuan dan pengamalan, antara gnosis dan proxis dalam kehidupan agama. Pendidikan agama menjadi pengajaran agama sehingga tidak mampu untuk membentuk pribadi-pribadi muslim. Di samping itu, kegiatan pendidikan agama yang berlangsung selama ini lebih banyak menyendiri, kurang berinteraksi dengan kegiatan-kegiatan pendidikan lainnya. ${ }^{3}$

Fakta ini didukung hasil penelitian yang menunjukan bahwa pembelajaran pendidikan agama Islam di sekolah tidak banyak memberikan pengaruh dalam pembentukan karakter anak didik. Kontribusi pembelajaran pendidikan agama Islam tidak lebih dari $20 \%$.

Menyikapi permasalahan di atas, diperlukan upaya cerdas dan solutif untuk mengatasinya. Upaya cerdas yang dimaksud adalah kembali kepada apa yang telah dilakukan Nabi Muhammad SAW dalam membina karakter umat Islam di Madinah. Sejarah telah mencatat bahwa Rasulullah dikenal sebagai pendidik yang telah berhasil dan sukses besar dalam melahirkan generasi yang memiliki keunggulan dalam bidang moral, sikap kepribadian, intelektual dan sosial. Dengan kata lain Rasulullah SAW

${ }^{1}$ Muhaimin, Nuansa Baru Pendidikan Islam: Mengurai Benang Kusut Dunia Pendidikan (Jakarta: PT. Raja Grafindo Persada, 2006), 35.

${ }^{2}$ Sutrisno, Pendidikan Islam Berbasis Problem Sosial (Yogyakarta: Ar-Ruzz Media, 2012), 76

${ }^{3}$ Mochtar Buchori, Posisi dan Fungsi Pendidikan Agama Islam dalam Kurikulum Perguruan Tinggi. Malang: IKIP Malang, 1992), 24 
berhasil merubah akhlak atau karakter jahiliyah menjadi akhlak yang Islami, yaitu itulah generasi sahabat. Generasi inilah yang selanjutnya disebut sebagai pelopor yang telah membuka jalan bagi generasi berikutnya dalam mengembangkan dan meningkatkan harkat dan martabat manusia.

Ada beberapa alasan kenapa mengkaji pola Rasulullah SAW dalam pembentukan karakter menjadi sangat penting. Mengutip apa yang dikemukakan oleh Abuddin Nata, bahwa di antara alasannya adalah sebagai berikut: pertama, bahwa Rasulullah SAW dinyatakan dalam al-Qur`an sebagai suri tauladan yang baik bagi umatnya. Kedua, zaman Rasulullah SAW adalah zaman yang telah berhasil melahirkan generasi yang memiliki keunggulan di bidang moral, sikap keagamaan, kepribadian, intelektual dan sosial. Ketiga, di dalam al-Qur`an maupun Hadis Nabi Muhammad SAW dinyatakan sebagai pendidik (Q.S. Al-Baqarah, 2: 129). Keempat, bahwa kehadiran Nabi di muka bumi ini adalah untuk menyempurnakan akhlak yang mulia. ${ }^{4}$

Berdasarkan pemikiran di atas, maka kajian terhadap pola pembentukan karakter Nabi SAW menjadi suatu yang urgen bagi perbaikan akhlak dan karakter bangsa ini. Adapun pendekatan yang digunakan adalah pendekatan normatif perenialis, yaitu kajian pembentukan karakter dari sumber ajaran Islam yang dijamin kebenarannya yaitu alQur`an dan Hadis.

\section{B. Karakter Islami}

Menurut bahasa, "karakter" berarti watak, sifat, tabiat. Berkarakter berarti mempunyai tabiat. ${ }^{5}$ Menurut Pusat Bahasa Depdiknas, sebagaimana dikutip Zubedi, karakter adalah bawaan, hati, jiwa, kepribadian, budi pekerti, prilaku personalitas, sifat, tabiat, temperamen watak. ${ }^{6}$ Karakter dapat juga diartikan sebagai watak, tabiat, akhlak, atau kepribadian seseorang yang terbentuk dari hasil internalisasi berbagai kebaikan yang diyakini dan digunakan sebagai landasan untuk cara pandang, berpikir, bersikap atau bertindak. Kemendiknas menyebutkan bahwa karakter adalah prilaku yang dilandasi oleh nilai-nilai berdasarkan norma agama, kebudayaan, hukum/konstitusi, adat istiadat, dan estetika.

\footnotetext{
${ }^{4}$ Abuddin Nata, Pendidikan dalam Perspektif Hadis (Jakarta: UIN Jakarta Press, 2005), 17.

${ }^{5}$ Peter Salim dan Yenny Salim, Kamus Bahasa Indonesia Kontemporer (Jakarta: Modern English Press, 2002), 102

${ }^{6}$ Zubaedi, Desain Pendidikan Karakter (Jakarta: Kencana, 2011), 67.
} 
Dalam Islam, karakter itu identik dengan akhlak. Akhlak menurut bahasa Arab, berarti perangai, tabiat, kelakuan, watak dasar, kebiasaan, peradaban yang baik, dan agama. ${ }^{7}$ Ibn Miskawaih (w. 421 H./1030 M.) mendefinisikan kata akhlak, yaitu "sifat yang tertanam dalam jiwa yang mendorongnya untuk melakukan perbuatan tanpa memerlukan pemikiran dan pertimbangan." "Imam al-Ghazali mengemukakan bahwa akhlaq adalah sifat yang tertanam dalam jiwa yang menimbulkan macam-macam perbuatan dengan gampang dan mudah, tanpa memerlukan pemikiran dan pertimbangan. ${ }^{9}$ Dalam Da irah al-Ma'arif, disebutkan bahwa akhlaq adalah "sifat-sifat manusia yang terdidik." ${ }^{10}$ Kata akhlak juga mengandung segi-segi persesuaian dengan khalq serta erat hubungannya dengan Khaliq dan makhluq. Dengan demikian, kata akhlak juga menunjukan pada pengertian adanya hubungan yang baik antara Khaliq dan makhluq yang diatur dalam agama Islam.

Abuddin Nata menyebutkan lima ciri yang terdapat dalam perbuatan akhlak, yaitu pertama, akhlak tersebut sudah menjadi kepribadian yang tertanam kuat dalam jiwa seseorang; kedua, perbuatan akhlak merupakan perbuatan yang dilakukan dengan tanpa pemikiran; ketiga, perbuatan akhlak adalah perbuatan tanpa paksaan dan tanpa ada unsur sandiwara; keempat, akhlak adalah perbuatan yang dilakukan untuk meninggikan kalimat Allah.

Dengan demikian, karakter Islami adalah prilaku, sifat, tabiat, akhlak yang dilandasi oleh nilai-nilai Islam yang bersumber dari al-Quran dan Hadis Nabi SAW. Karakter Islami ini intinya adalah akhlaq al-karimah. Akhlaq al-karimah adalah suatu sifat, tabiat dan prilaku yang menunjukan adanya hubungan baik dengan Allah (Khaliq) dan sesama makhluk yang didasari oleh nilai-nilai Islam. Di antara contoh akhlaq alkarimah, yang berhubungan dengan Allah, adalah Iman dan cinta kepada Allah, taat, patuh, tawakkal, syukur, ridha/ikhlas, tobat, cinta damai. (H.R. Muslim No. 4634, 4638, 4640), bersahabat/komunikatif (H.R. Muslim No. 4621, 4623,4624,4625, 4627, dan lain-lain), peduli sosial (H.R. Muslim No. 4660,4661, 4677, 4756, 4761, dan lain-lain), sabar (H.R. Muslim No. 4673, 4722, 4725, 4770), peduli lingkungan (H.R. Muslim No. 4699, 4736, 4742, dan lain-lain), kejujuran (H.R. Muslim No. 4714, 4717, 4718, dan

\footnotetext{
${ }^{7}$ Jamil Shaliba, Al-Mu'jam al-Falsafi, Juz 1 (Mesir: Dar al-Kitab al-Misri, 1978), 112 ${ }^{8}$ Ibn Miskawaih, Tahdzib al-Akhlaq wa Tathhir al-A'raq (Mesir: al-Mathba'ah al-Mishriyah, 1934), 2

${ }^{9}$ Al-Ghazali, Ihya' 'Ulum al-Din (Beirut: Dar al-Fikr, t.th.), 124

${ }^{10 ‘}$ Abd al-Hamid, Da`irah al-Ma'arif (Kairo: Al-Sya'b, t.th), 175.
} 
lain-lain), religiusitas (H.R. Muslim No. 4753, 4772, 4691), rendah hati (H.R. Muslim No. 4752, 4754, 4755), menghargai prestasi (H.R. Muslim No. 4651, 4780), rasa ingin tahu (H.R. Muslim No. 4632, 4768), toleransi (H.R. Muslim No. 4629), semangat kebangsaan (H.R. Muslim No. 4681).

Dengan demikian, pembentukan karakter Islami merupakan upaya yang terencana dan sistematis untuk menjadikan seseorang mengenal, peduli dan menginternalisasikan nilai-nilai Islam sehingga seseorang tersebut berprilaku sebagai insan kamil.

Pendidikan karakter memiliki makna yang lebih tinggi dari pada pendidikan moral, karena bukan sekedar mengajarkan mana yang benar dan mana yang salah. Lebih dari itu, pendidikan karakter menanamkan kebiasaan tentang yang baik, sehingga anak menjadi paham, mampu merasakan dan mau melakukan yang baik.

\section{Pola Rasulullah dalam Pembentukan Karakter Islami}

Sejarah telah mencatat keberhasilan pola pendidikan Rasulullah dalam mengubah tradisi ke-jahiliyah-an kepada tradisi Islam dan merupakan prestasi yang paling cemerlang yang pernah terjadi di muka bumi dalam bidang pendidikan. Gambaran keberhasilan beliau sebagaimana diungkapkan oleh Sofyan Sauri adalah bahwa Rasulullah SAW berhasil mendidik sahabatnya menjadi masyarakat yang berkualitas dan berkarakter, sehingga mereka rindu kepada kebenaran, semangat menuntut ilmu, merasa mulia degan Islam, sederhana dalam bersikap, di malam hari mereka menangis ber-taqarrub kepada Allah SWT, di siang hari berjihad melawan kemusyrikan, kekafiran dan kezaliman, memerintahkan kebaikan dan melarang kejahatan terhadap kaum muslimin, serta menebarkan kasih sayang dengan cara menghilangkan beban-beban mereka. ${ }^{11}$

Rasulullah SAW berhasil membuat kaum muslimin saling mengasihi dan saling mencintai sesama mereka, sebagaimana diungkapkan oleh Allah SWT dalam al-Quran di dalam surat al-Hasyr ayat 9, yang artinya adalah: "Orang-orang yang telah menempati kota Madinah dan telah beriman (Anshor) sebelum kedatangan mereka (Muhajirin), mereka (Anshor) mencintai orang-orang yang berhijrah kepada mereka

${ }^{11}$ Sofyan Sauri, Filsafat dan Teosofat Akhlak (Kajian Filosofis dan Teosofis tentang Akhlak, Karakter, Nilai, Moral, Etika, Budi Pekerti, Tata Krama, Sopan Santun). (Bandung: Rizqi Press, 2011), 89 
(Muhajirin) dan mereka (Anshor) tiada menaruh keinginan dalam hati mereka terhadap apa-apa yang diberikan kepada mereka (Muhajirin), dan mereka mengutamakan (orang-orang muhajirrin), atas diri mereka sendiri, sekalipun mereka dalam kesusahan, dan siapa yang yang dipelihara dari kekikiran dirinya, mereka itulah orang-orang yang beruntung."

Rasulullah SAW mampu menanamkan karakter dan sifat jujur pada diri Abu Bakar, karakter bertanggung jawab dan peduli terhadap masyarakat pada diri Umar bin Khaththab, karakter peduli sosial yang terdapat pada diri Usman bin 'Affan, karakter cinta ilmu, patuh dan taat yang telah mengkristal dalam diri Ali bin Abi Thalib dan sahabat-sahabat lainnya.

Setelah mencermati keberhasilan Rasulullah SAW dalam melakukan pendidikan karakter para sahabatnya, maka timbul pertanyaan bagaimana pola yang digunakan Nabi SAW dalam membentuk karakter sahabat-sahabatnya hingga menjadi generasi unggul dalam berbagai karakter Islami? Berikut ini penulis mencoba untuk mengemukakan beberapa pola pembentukan karakter sahabat, yaitu:

1. Berawal dari pendidik yang berkarakter

Secara bahasa, pendidik adalah "orang yang mendidik."12 Dalam bahasa Inggris, terdapat beberapa kata yang memiliki arti yang berdekatan dengan pendidik, yaitu teacher dan tutor. Dalam bahasa Arab dijumpai kata ustadz, mudarris, mu'allim, dan muaddib. Beberapa istilah ini secara keseluruhan mengacu kepada seseorang yang memberikan pengetahuan, ketrampilan atau pengalaman kepada orang lain.

Dalam perspektif Islam, pendidik menempati posisi yang sangat penting dalam proses pendidikan atau pembentukan karakter Islami, baik pendidik dalam makna orangtua, guru maupun masyarakat. Dialah yang bertanggungjawab terhadap perkembangan anak didiknya. Potensi kognitif, afektif, dan psikomotorik yang terdapat pada anak didik harus diperhatikan perkembangannya agar tujuan pendidikan/ pembentukan karakter dapat tercapai seperti yang diharapkan. Adapun para pendidik menurut al-Qur’an dan Hadis adalah Allah SWT, Nabi Muhammad SAW, para orang tua dan orang lain.

Dalam pembentukan karakter Islami pada anak di dalam keluarga, orang tua merupakan faktor yang sangat fundamen/mendasar. Orangtua adalah pembina

\footnotetext{
${ }^{12}$ W.J.S. Poerwadarminta, Kamus Umum Bahasa Indonesia (Jakarta: Balai Pustaka, 1991), 97
} 
kepribadian dan karakter anak yang utama dan pertama. Orangtua juga sebagai perawat kejiwaan anak. Oleh karena itu orang tua yang bisa membentuk karakter baik pada seorang anak adalah orangtua yang berkarakter. Bagaimana mungkin melahirkan anak yang berkarakter jika orangtuanya tidak berkarakter. Seperti kata pepatah Arab: "Orang yang tak punya tidak akan pernah memberi." Pendidik yang berkarakter akan melahirkan anak yang berkarakter.

Oleh karena itulah Nabi SAW mengisyaratkan bahwa pembentukan karakter Islami sudah dimulai sejak pemilihan jodoh calon orang tua sang anak yang akan dilahirkannya. Sebagaimana dalam hadis yang artinya: "Perempuan dinikahi karena empat hal, yaitu karena hartanya, nasabnya, kecantikan dan agamanya. Maka pilihlah karena agamanya."

Kenapa harus memilih yang beragama? Karena agama akan menjadi panutan mereka dalam berumah tangga dan dalam menjalani kehidupan dunia. Dengan demikian, alasan pemilihan tersebut bukan hanya untuk kepentingan pasangan yang menikah tapi justru karena untuk calon anaknya yang akan dilahirkan di masa yang akan datang. Makanya salah satu kewajiban orangtua terhadap anaknya adalah mencarikan jodoh anaknya dengan orang yang baik agamanya. Dan ini bentuk persiapan orangtua terhadap calon cucunya nanti.

Rasulullah SAW berhasil membentuk karakter sahabat karena beliau adalah pribadi yang berkarakter, pendidik yang profesional. Sebagai pribadi yang berkarakter, Rasulullah SAW selalu menampilkan sifat lemah lembut, peduli, tegas, kerja keras, mau berbagi, konsisten, sehingga sahabat sangat mencintai dan merindukannya. Sebagai seorang pendidik profesional, Nabi SAW tampil sebagai guru yang menguasai banyak disiplin ilmu. Ia mengajarkan al-Qur`an secara langsung kepada para pengikutnya, serta membimbingnya agar hidup pada jalan yang benar sesuai dengan ajaran al-Qur`an, ia mengangkat dirinya sebagai guru pada geneologi dan ilmu alat bunyi. Di samping itu, Rasulullah SAW juga tampil sebagai tokoh yang terlibat langsung dalam memecahkan masalah (problem solver), seperti masalah kemasyarakatan, sosial, keagamaan dan sebagainya yang muncul di tengah-tengah masyarakat sesuai dengan petunjuk Allah dalam al-Qur`an adalah pendidik yang berkarakter atau dikenal dengan istilah uswatun hasanah/contoh tauladan yang baik, sebagaimana yang telah diungkapkanNya dalam alQur`an. Allah SWT telah memilihnya menjadi nabi dan contoh tauladan yang baik bagi 
umatnya. Oleh karena itu, Allah SWT telah mempersiapkannya menjadi sosok yang baik.

\section{Berbasis Agama}

Pembentukan karakter Islami tidak bisa dipisahkan dengan proses pendidikan Islam. Sebab inti dari pendidikan Islam itu adalah menanamkan dan membentuk akhlak/karakter yang Islami kepada peserta didik. Pendidikan Islam adalah pendidikan akhlak untuk kebaikan kehidupan manusia, mewujudkan keseimbangan yang sempurna pada kepribadian, menggabungkan antara iman, akhlak, ilmu dan amal. Pendidikan tidak akan bermakna tanpa unsur-unsur itu. Tujuan pendidikan Islam adalah mendidik muslim agar menjadi beradab. Inilah yang membedakan pendidikan Islam dengan pendidikan Barat. Pendidikan Barat hanya mampu membuat seseorang menjadi trampil/profesional. Pendidikan Islam membuat seseorang memiliki iman yang kuat, akhlak yang mulia, ilmu yang luas serta amal yang banyak. Adapun prinsip pendidikan/pembentukan karakter Islami, adalah:
a. Menjadikan Allah SWT sebagai tujuan
b. Memperhatikan perkembangan akal/rasional
c. Memperhatikan perkembangan kecerdasan emosional
d. Melalui keteladan dan pembiasaan.

Menurut Azyumardi Azra, ada beberapa karakteristik pendidikan Islam, yaitu:

Pertama, penguasaan ilmu pengetahuan. Ajaran dasar Islam mewajibkan mencari ilmu pengetahuan bagi setiap muslim dan muslimat. Setiap Rasul yang diutus Allah lebih dahulu dibekali ilmu pengetahuan, dan mereka diperintahkan untuk mengembangkan llmu pengetahuan itu.

Kedua, pengembangan ilmu pengetahuan. Ilmu yang telah dikuasai harus diberikan dan dikembangkan kepada orang lain. Nabi Muhammad SAW sangat membenci orang yang memiliki ilmu pengetahuan, tetapi tidak mau memberi dan mengembangkan kepada orang lain.

Ketiga, penekanan pada nilai-nilai akhlak dalam penguasaan dan pengembangan ilmu penetahuan. Ilmu pengetahuan yang didapat dari pendidikan Islam terikat oleh nilai-nilai akhlak.

Keempat, penguasaan dan pengembangan ilmu pengetahuan, hanyalah untuk pengabdian kepada Allah dan kemaslahatan umum. 
Kelima, penyesuaian terhadap perkembangan anak. Sejak awal perkembangan Islam, pendidikan Islam diberikan kepada anak sesuai umur, kemampuan, perkembangan jiwa, dan bakat anak. Setiap usaha dan proses pendidikan haruslah memperhatikan faktor pertumbuhan anak. Fazhur Rahman berkata: "Heart of people have desires and aptitudes; sometimes they are ready to listen and others time are not. Enter to people's hearts through their aptitudes. Talk to them when they ready to listen. For the condition of heart is such that you force to do something, then it becomes blind (and refuses to accept it)."

Keenam, pengembangan kepribadian. Bakat alami dan keamampuan pribadi tiap-tiap anak didik diberikan kesempatan berkembang sehingga bermanfaat bagi dirinya dan masyarakat. Setiap murid dipandang sebagai amanah Tuhan, dan seluruh kemampuan fisik \& mental adalah anugerah Tuhan. Perkembangan kepribadian itu berkaitan dengan seluruh nilai sistem Islam, sehingga setiap anak dapat diarahan untuk mencapai tujuan Islam.

Ketujuh, penekaanan pada amal saleh dan tanggung jawab. Setiap anak didik diberi semangat dan dorongan untuk mengamalkan ilmu pengetahuan sehingga benarbenar bermanfaat bagi diri, keluarga dan masyarakat secara keseluruhan. Amal saleh dan tanggung jawab itulah yang menghantarkannya kelak kepada kebahagiaan di hari kemudian.

Dengan karakteristik-karakteristik pendidikan tersebut tampak jelas keunggulan pendidikan Islam dibanding dengan pendidikan lainnya. Karena, pendidikan dalam Islam mempunyai ikatan langsung dengan nilai-nilai dan ajaran Islam yang mengatur seluruh aspek kehidupannya atau berbasis agama Islam.

\section{Berbasis Masjid}

Untuk melaksanakan fungsi utamanya sebagai pendidik, Rasulullah SAW telah membuat kebijakan yang sangat penting dalam bidang pendidikan. Kebijakan pertama yang diambil beliau adalah membangun masjid di Quba dan dilanjutkan dengan membangun masjid Nabawi di Madinah. Masjid digunakan sebagai pusat kegiatan pendidikan dan dakwah, pembinaan moral, spritual, mengajarkan agama kepada kaum Muhajirin dan Anshor, membina sikap kebangsaan. Dengan kata lain, masjid telah 
digunakan oleh Rasulullah SAW sebagai tempat yang paling efektif dalam menyusun dan menghimpun potensi umat Islam. ${ }^{13}$

Adapun Fungsi masjid pada masa Nabi SAW adalah: (1) masjid sebagai pusat ibadah mahdhah, seperti sholat, zikir, dan baca al-Qur`an; (2) masjid sebagai tempat pengobatan korban perang/poliklinik; (3) masjid sebagai tempat mengatur strategi perang; (4) masjid pusat untuk mendamaikan seseorang atau kelompok yang sedang berbantah-bantahan; (5) masjid tempat menyambut tamu; (6) masjid tempat proses belajar mengajar, pendidikan kepribadian dalam bentuk qauli dan fi'liy; (7) masjid tempat menahan tawanan perang; dan (8) masjid tempat konsultasi masalah ekonomi, sosial.

\section{Implikasi Pola Pembentukan Karakter Islami ala Rasulullah pada Jalur Pendidikan Non Formal}

Sebelum membahas implikasi pola pembentukan karakter Islami Rasulullah SAW, terlebih dahulu dibahas tentang makna jalur pendidikan non formal. Menurut Undang-Undang Nomor 20 Tahun 2003 tentang Sistem Pendidikan Nasional, pasal 1 ayat 7 bahwa jalur pendidikan adalah wahana/alat yang dilalui oleh peserta didik untuk mengembangkan potensi diri dalam suatu peroses pendidikan yang sesuai dengan tujuan. Pasal 13 ayat 1 berbunyi bahwa jalur pendidikan terdiri atas pendidikan formal, informal dan nonformal yang saling melengkapi dan memperkaya. Pasal 26 ayat 1 berbunyi bahwa pendidikan nonformal diselenggarakan bagi masyarakat yang memerlukan layanan pendidikan yang berfungsi sebagai pengganti, penambah, dan/atau pelengkap pendidikan formal dalam rangka mendukung pendidikan sepanjang hayat. Pasal 26 ayat 2 berbunyi pendidkan nonformal berfungsi mengembangkan potensi peserta didik dengan penekanan pada penguasaan pengetahuan dan ketrampilan fungsional serta pengembangan sikap dan kepribadian profesional. Pada pasal 26 ayat 3 berbunyi bahwa pendidikan non formal meliputi pendidikan kecakapan hidup, pendidikan anak usia dini, pendidikan kepemudaan, pendidikan pemberdayaan perempuan, pendidikan keaksaraan, pendidikan ketrampilan dan pelatihan kerja, pendidikan kesetaraan serta pendidikan lainnya yang ditujukan untuk mengembangkan kemampuan peserta didiuk. Pasal 20 ayat 4 berbunyi bahwa satuan pendidikan

\footnotetext{
${ }^{13}$ M. Natsir, Fiqh al-Da'wah (Jakarta: Dewan Dakwah Islamiyah, 1985), 65.
} 
nonformal terdiri atas lembaga kursus, lembaga pelatihan, kelompok belajar, pusat kegiatan belajar masyarakat dan majelis taklim serta satuan pendidikan yang sejenis.

Dengan demikian, jalur pendidikan nonformal adalah wahana untuk mengembangkan potensi seseorang peserta didik dalam suatu proses pendidikan yang berfungsi sebagai penambah atau pelengkap pendidikan formal dan informal dalam bentuk lembaga kursus, lembaga pelatihan, kelompok belajar atau majlis taklim dan hasilnya dapat dihargai setara dengan pendidikan formal sesuai dengan ketentuan yang berlaku.

Selanjutnya pembentukan karakter Islami membutuhkan waktu yang panjang. Rasulullah SAW saja membutuhkan waktu selama 23 tahun untuk merubah karakter kejahiliyyah-an para sahabat menjadi karakter Islami. Berikut ini ada beberapa implikasi pola pembentukan karakter Islami yang telah dilakukan oleh Rasulullah SAW pada jalur pendidikan nonformal, yaitu:

1. Memfungsikan masjid sebagai pusat kegiatan jalur pendidikan non formal.

Masjid adalah tempat sujud dan sekaligus merupakan simbol kepatuhan dan ketaatan kepada Allah SWT. Sebagai tempat sujud, masjid dapat mengontrol prilaku seseorang. Seseorang yang datang ke masjid tentu tidak dapat berbuat semena-mena sebagaimana ia berada di tempat selain masjid. Dengan difungsikannya masjid sebagai pusat kegiatan pendidikan nonformal maka akan dapat memberikan dampak positif kepada orang-orang yang terlibat dalam kegiatan tersebut. Setidak-tidaknya, akan mendorongnya untuk dapat melakukan sholat berjamaah dan dapat membuat hatinya terpaut / tergantung pada masjid.

2. Pembina, pelaksana kegiatan seharusnya orang-orang yang berkarakter dan hatinya terpaut pada masjid.

Keberhasilan suatu kegiatan akan dipengaruhi oleh pelaku dan orang-orang yang terlibat dalam kegiatan tersebut. Agar kegiatan pendidikan nonformal ini dapat berkontribusi dalam pembentukan karakter islami, maka pembina, pelaksana kegiatan sebaiknya adalah orang-orang yang berkarakter dan hatinya terpaut pada masjid.

3. Orientasi kegiatan seharusnya mengarah pada masalah iman, akhlak, ilmu dan amal.

Agar kegiatan pendidikan nonformal dapat memberikan makna yang berarti pada peserta didik dan pendidiknya maka pelaksanaan kegiatannya sebaiknya berbasis 
agama Islam, dengan kata lain dapat menambah dan memperkuat keimanan peserta didiknya pada Allah SWT dan Rasul-Nya, berakhlak mulia serta dapat menambah ilmu serta berpeluang untuk melakukan amal.

4. Membentuk perkumpulan, organisasi sosial yang Islami dan dipelopori oleh kaum muda muslim dan bersinergi dengan pembentukan karakter dalam keluarga dan masyarakat.

Dahsyatnya dampak globalisasi akibat kemajuan teknologi informasi dan komunikasi saat ini, menuntut kreatifitas kaum muda muslim untuk dapat menjadi garda terdepan untuk mengatasi berbagai dampak negatif yang dimunculkan oleh kemajuan tersebut. Untuk itu, perlu membentuk komunitas atau perkumpulan/organisasi sosial yang islami dan bersinergi dengan orangtua, tokoh masyarakat bahkan pihak pemerintah agar karakter bangsa ini tidak dirusaki oleh nilai-nilai yang masuk melalui alat komunikasi dan informasi yang ada saat ini.

\section{E. Kesimpulan}

Membentuk karakter Islami pada jalur pendidikan nonformal dapat dilakukan dengan mengacu pada pola pembentukan karakter Islami yang telah dicontohkan oleh Rasulullah SAW dengan hasil dan pencapaian yang sangat luar biasa dan keberhasilannya diakui oleh seluruh dunia.

\section{F. Daftar Pustaka}

Al-Ghazali. Ihya' 'Ulum al-Din. Beirut: Dar al-Fikr, t.th.

Al-Hamid 'Abd. Da irah al-Ma'arif. Kairo: Al-Sya'b, t.th.

Buchori, Mochtar. Posisi dan Fungsi Pendidikan Agama Islam dalam Kurikulum Perguruan Tinggi. Malang: IKIP Malang, 1992.

Miskawaih, Ibn. Tahdzib al-Akhlaq wa Tathhir al-A'raq. Mesir: al-Mathba'ah alMishriyah, 1934.

Muhaimin. Nuansa Baru Pendidikan Islam: Mengurai Benang Kusut Dunia Pendidikan. Jakarta: PT. Raja Grafindo Persada, 2006.

Nata, Abuddin. Pendidikan dalam Perspektif Hadis. Jakarta: UIN Jakarta Press, 2005.

Natsir, M. Fiqh al-Da'wah. Jakarta: Dewan Dakwah Islamiyah, 1985

Poerwadarminta, W.J.S. Kamus Umum Bahasa Indonesia. Jakarta: Balai Pustaka, 1991.

Salim, Peter dan Salim, Yenny. Kamus Bahasa Indonesia Kontemporer. Jakarta: Modern English Press, 2002. 
Sauri, Sofyan. Filsafat dan Teosofat Akhlak (Kajian Filosofis dan Teosofis tentang Akhlak, Karakter, Nilai, Moral, Etika, Budi Pekerti, Tata Krama, Sopan Santun). Bandung: Rizqi Press, 2011.

Shaliba, Jamil. Al-Mu'jam al-Falsafi. Juz 1. Mesir: Dar al-Kitab al-Misri, 1978.

Sutrisno. Pendidikan Islam Berbasis Problem Sosial. Yogyakarta: Ar-Ruzz Media, 2012.

Zubaedi. Desain Pendidikan Karakter. Jakarta: Kencana, 2011. 